\title{
Mother-to-Child HIV Transmission Factors in Exposed Children at University Hospital Center of Treichville (Abidjan, Cote d'Ivoire)
}

\author{
Edouard N'Guessan, Jean Marc Lamine Dia, Mouhideen Oyelade, Ignace Yao, Privat Guié, \\ Simplice Anongba
}

Department of Obstetrics and Gynecology, University Hospital of Treichville, Abidjan, Côte d'Ivoire

Email: edouardnguessan@yahoo.fr

How to cite this paper: N'Guessan, E., Dia, J.M.L., Oyelade, M., Yao, I., Guié, P. and Anongba, S. (2017) Mother-to-Child HIV Transmission Factors in Exposed Children at University Hospital Center of Treichville (Abidjan, Cote d'Ivoire). Open Journal of Obstetrics and Gynecology, 7, 1198-1208.

https://doi.org/10.4236/ojog.2017.712122

Received: October 21, 2017

Accepted: November 25, 2017

Published: November 28, 2017

Copyright $\odot 2017$ by authors and Scientific Research Publishing Inc. This work is licensed under the Creative Commons Attribution International License (CC BY 4.0).

http://creativecommons.org/licenses/by/4.0/

\begin{abstract}
Background: The elimination of HIV transmission from mother to child is currently possible. Côte d'Ivoire, which has a $4.6 \%$ HIV prevalence among women, is one of 22 pilot countries for the elimination of mother-to-child transmission of HIV. Since 2015, Côte d'Ivoire has adopted new strategies according to the WHO B+ guidelines. Objective: To identify factors associated with mother-to-child HIV transmission in children born of seropositive mothers managed at Treichville university hospital. Material and methods: A case-control study was conducted in the obstetrics department at Treichville university hospital, between January 2013 and December 2015. It involved children born to mothers infected with HIV, whose first PCR (Polymerase Chain Reaction) result was available during this period. A standardized questionnaire on data related to exposed children and their mother was used. Factors associated with mother-to-child HIV transmission were investigated using logistic regression. Results: A total of $214 \mathrm{HIV}$-exposed children were included in the study with a sex ratio of 0.9 . The majority of the children were born by vaginal route $(52.8 \%)$ and received post-exposure prophylaxis (88.3\%) and replacement feed (51.9\%). Their mothers received antiretroviral therapy during pregnancy in $45.3 \%$ of the cases. The first PCR was performed at the sixth week of life in $52.3 \%$ of cases. The prevalence of HIV infection in exposed children was $7.5 \%(95 \% \mathrm{CI}=4.5 \%-11.8 \%)$. In multivariate analysis, the absence of antiretroviral prophylaxis in children $[\mathrm{aOR}=4.3,95 \%$ (1.2 to 15.6), $\mathrm{p}=0.03$ ], the mixed feed [aOR $=3.8,95 \%(1.1-13.1), \mathrm{p}<0.03$ ], the failure to take antiretroviral regimen during pregnancy $[\mathrm{aOR}=8.0,95 \% \mathrm{CI}$ (1.9 - 32.4), $\mathrm{p}<0.003$ ], were associated with mother-child HIV transmission. Conclusion: The mother-to-child HIV transmission rate remains high in our practice. Strategies to reduce situations that do not comply with current
\end{abstract}


recommendations should be considered to prevent mother-to-child HIV transmission.

\section{Keywords}

HIV-Exposed Children, Mother-to-Child Transmission, DBS/PCR

\section{Introduction}

Mother-to-child HIV transmission remains a major public health issue in sub-Saharan Africa. Indeed, according to UNAIDS, 160,000 children have been newly infected with HIV in 2016, mainly through mother-to-child transmission. And these infections occurred in $85.6 \%$ of cases in sub-Saharan Africa [1].

Moreover, HIV infection is more aggressive in children since half of infected children die before their second birthday in absence of adequate treatment [2].

In developed countries, the elimination of mother-to-child HIV transmission has been effective since the early 2000s, thanks to wide distribution of antiretroviral therapy during pregnancy. In fact, studies from Europe and the US reported mother-to-child transmission rates of HIV less than 1\% [3] [4]. However, the majority of studies in our subregion reported generally high rates of mother-to-child transmission. These rates were $12.3 \%$ in the Saizonou study in Benin [5] and $16.9 \%$ in the Imade study in Nigeria [6].

In resource-limited countries, significant efforts have also been made in recent years towards the elimination of mother-to-child HIV/AIDS transmission. Concerning Côte d'Ivoire, the culmination of these achievements was the adoption of Option B+ of WHO in 2015 [7]. The implementation of this new strategy justifies updating the epidemiological data on the mother-to-child transmission of HIV. The objective of this work was to report, in our practice, the prevalence and factors associated with mother-to-child HIV transmission in exposed children.

\section{Materials and methods}

\subsection{Materials}

\section{- Type and site of study}

This is a single-center case-control study conducted over a period of three years, from January 2013 to December 2015. It was conducted in the obstetrics and gynecology department at Univeristy Hospital Center of Treichville (CHUT) which is one of the three level 3 maternities of reference of Abidjan. This service has a screening and medical managementunit for people living with HIV. This unit is run by a team including obstetrician-gynecologists, pediatricians, pharmacists, laboratory technicians, midwives, social workers, community counselors and data managers. The pediatricians essentially carry out the medical follow-up of children exposed to HIV until knowledge of their 
definitive HIV status.

\section{- Study population}

The study focused on HIV exposed children (born to HIV positive mothers) who were followed in our department during the study period. Were included all the exposed childrenwhose follow up was effective until they got their definitive HIV status.

We excluded from the study children having incomplete files, children whose PCR/DBS (Polymerase Chain Reaction by Dried Blood Spot) was not yet available, and children born out of the service.

\subsection{Methods}

\section{- Diagnosis of HIV status of children}

The diagnosis of HIV infection in exposed children was based on the realization of a PCR/DBS from the sixth week of life.

- Data collection and variables studied

To carry out this work, we developed a standardized questionnaire including the different variables needed for our study. Follow-up records of HIV-exposed children, delivery records, and care records for people living with HIV from mothers were used as a basis for data collection.

The data collection was made on a standardized questionnaire from the follow up records of children exposed to HIV, birth registers, and the mother management sheets. The data were collected from trained investigators who were all doctors.The main variable studied was the HIV status of exposed children which has been defined in two classes: "HIV positive" or "HIV negative". The other variables studied concerning children were: mode of delivery, birth weight, sex, age of PCR, antiretroviral prophylaxis, cotrimoxazole prophylaxis and the type of foodIn the mothers the variable studied were: age, profession, level of education, marital status, parity, number of antenatal consultation, timing of HIV testing, revelation of HIV status to the spouse and the antiretroviral treatment during pregnancy.

- Statistical analysis

Data analysis was performed using the SPSS.22 software. A descriptive analysis was first performed. A logistic regression was used to identify risk factors for mother-to-child HIV transmission (dependent variable). In univariate analysis the variables were compared using the chi 2 test or Fischer test (when recommended). We have included in the multivariate model independent variables associated with the mother-child HIV transmission in the univariate analysis with a significance level of $<0.20$. A value $\mathrm{p}<0.05$ was used as the threshold of significance. Odds ratios with a confidence interval of $95 \%$ were calculated for each of the risk factors for mother-child HIV transmission.

\section{Results}

\subsection{Description of Study Population}

Of the 358 HIV-exposed children recorded during the study period, 214 were 
included in the study, representing a response rate of $59.8 \%$ (Figure 1 ).

Out of the 214 children, $114(53.3 \%)$ were female. The first PCR was performed at the sixth week of life in $52.3 \%$ of cases. With a median birth weight of $2925 \mathrm{~g}$ (interquartile: 2600 - $3200 \mathrm{~g}$ ), more than half of them (52.8\%) were born vaginally. Overall, $88.3 \%$ of children had antiretroviral prophylaxis and replacement feeding for $51.9 \%$ of them (Table 1 ).

The characteristics of mothers of HIV exposed infants are shown in Table 2. The median age of the mothers was 34 years (interquartile: 31 - 37 years), HIV seropositivity was known prior to pregnancy in less than half of the cases (42.5\%). The majority of them did not reveal their HIV status to their spouses (53.7\%), and hadn't received antiretroviral tritherapy during pregnancy $(54.7 \%)$.

\subsection{Prevalence of HIV Infection in Exposed Children}

Of the 214 children in our series, 16 were infected with HIV. The prevalence of HIV infection in exposed children was therefore $7.5 \%$ with a $95 \%$ confidence interval (CI) between 3.9\% - 11.0\%.

\subsection{Factors Associated With Mother-to-Child Transmission}

The multivariate analysis showed that the absence of antiretroviral prophylaxis in children $[\mathrm{aOR}=4.3,95 \% \mathrm{CI}(1.2-15.6), \mathrm{p}=0.03$ ], the mixed feeding $[\mathrm{aOR}=$ $3.8,95 \% \mathrm{CI}(1.1-13.1), \mathrm{p}<0.03], \mathrm{p}<0.009$ ] and the failure of an antiretroviral regimen during pregnancy $[\mathrm{aOR}=8.0,95 \% \mathrm{CI}(1.9-32.4), \mathrm{p}<0.003]$, were significantly associated with mother to child HIV transmission (Table 3 ).

\section{Discussion}

The prevalence of HIV infection in children exposed in our series was very high (7.5\%) compared to the rate of transmission from mother to child of HIV

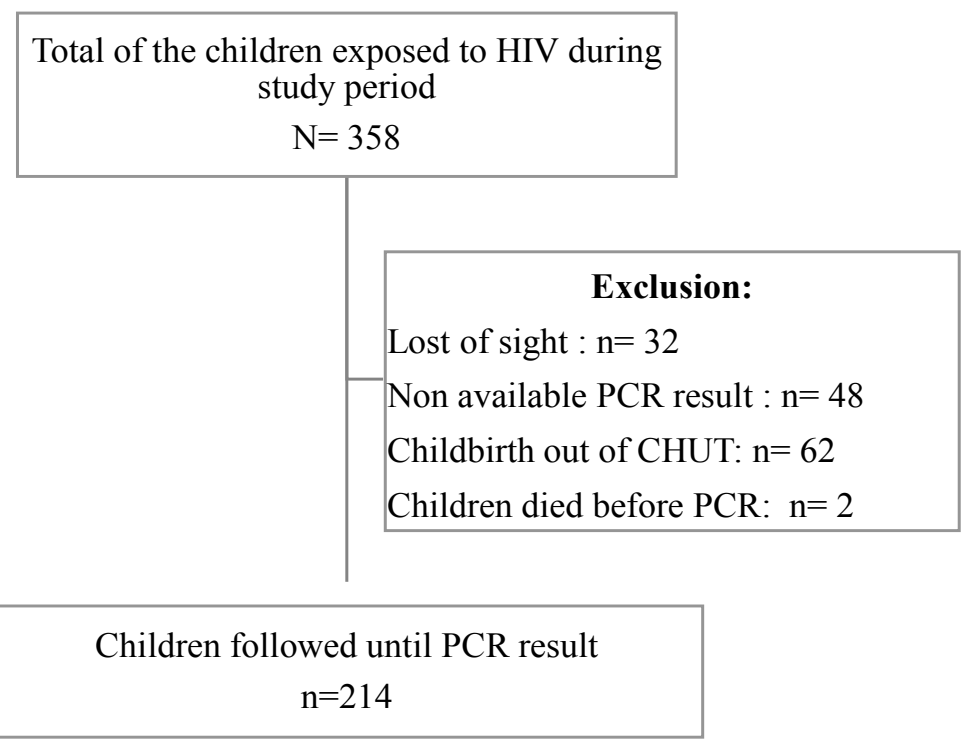

Figure 1. Diagram explaining the enrollment process in the study. 
Table 1. Characteristics of HIV exposed children in the study.

\begin{tabular}{|c|c|c|}
\hline Characteristics & Population & Percentage $(\%)$ \\
\hline \multicolumn{3}{|l|}{ Age at first PCR test } \\
\hline - At 6 weeks & 112 & 52.3 \\
\hline - 7 weeks to 6 months & 83 & 38.8 \\
\hline - After 6 months & 19 & 8.9 \\
\hline \multicolumn{3}{|l|}{ Sex } \\
\hline - Female & 114 & 53.3 \\
\hline Male & 100 & 46.7 \\
\hline \multicolumn{3}{|l|}{ Birth weight (grams) } \\
\hline$<2500$ & 42 & 19.6 \\
\hline $2500-3999$ & 165 & 77.1 \\
\hline$\geq 4000$ & 7 & 3.3 \\
\hline \multicolumn{3}{|l|}{ Childbirth mode } \\
\hline - Vaginally & 113 & 52.8 \\
\hline - Elective caesarean section & 84 & 38.8 \\
\hline - Caesarean section in emergency & 17 & 7.9 \\
\hline \multicolumn{3}{|l|}{ Antiretroviral (ARV) prophylaxis of children } \\
\hline - Yes & 189 & 88.3 \\
\hline - No & 25 & 11.7 \\
\hline \multicolumn{3}{|l|}{ Cotrimoxazoleprophylaxis } \\
\hline - Yes & 164 & 76.6 \\
\hline - No & 50 & 23.4 \\
\hline \multicolumn{3}{|l|}{ Feeding pratice } \\
\hline Feeding replacement & 111 & 51.9 \\
\hline Exclusive Breastfeeding & 54 & 25.2 \\
\hline Mixed feeding & 49 & 22.9 \\
\hline
\end{tabular}

reported in the western series that are less than 1\% [8] [9].

There are some studies in sub-Saharan Africa that have reported rates of mother-to-child transmission of HIV close to those of industrialized countries. Thus, Martin [10] in Angola and Technau [11] in South Africa, reported in their studies, the respective mother-child transmission rates of $4.1 \%$ and $1.8 \%$. It should be noted that the reported rates in the majority of studies conducted in countries with limited resources, are generally higher than 10\% [12] [13] [14]. These differences are certainly related not only to low rates of antiretroviral treatment coverage in pregnant women in our countries with limited resources but also to the inhomogeneity of antiretroviral regimens for mother-to-child transmission of HIV in these studies. In our series, only $43.5 \%$ of pregnant women underwent antiretroviral tritherapy. 
Table 2. Characteristics of mothers of HIV exposed children during the study.

\begin{tabular}{|c|c|c|}
\hline Characteristics & Population & Percentage (\%) \\
\hline \multicolumn{3}{|l|}{ Maternal age (years) } \\
\hline - $\quad 20-29$ & 35 & 16.4 \\
\hline - $\quad 30-39$ & 159 & 74.3 \\
\hline - $\quad \geq 40$ & 20 & 9.3 \\
\hline \multicolumn{3}{|l|}{ Number of children } \\
\hline - 1 & 76 & 35.5 \\
\hline $2-3$ & 108 & 50.5 \\
\hline$\geq 4$ & 30 & 10 \\
\hline \multicolumn{3}{|l|}{ Profession } \\
\hline Liberal & 108 & 50.5 \\
\hline Employee & 47 & 21.9 \\
\hline Household & 35 & 16.4 \\
\hline Students & 24 & 11.2 \\
\hline \multicolumn{3}{|l|}{ Level of school education } \\
\hline None and primary & 33 & 15.4 \\
\hline - Secondary and higher & 181 & 84.6 \\
\hline \multicolumn{3}{|l|}{ Marital status } \\
\hline - Single & 63 & 29.4 \\
\hline - In a relationship & 151 & 70.6 \\
\hline \multicolumn{3}{|l|}{ Number of antenal consultation } \\
\hline - $1-3$ & 10 & 4.7 \\
\hline$\geq 4$ & 204 & 95.3 \\
\hline \multicolumn{3}{|l|}{ Period of HIV testing } \\
\hline Before pregnancy & 91 & 42.5 \\
\hline During Pregnancy & 101 & 47.2 \\
\hline Maternity & 22 & 10.3 \\
\hline \multicolumn{3}{|l|}{ Revealing HIV status to spouse } \\
\hline Yes & 99 & 46.3 \\
\hline No & 115 & 53.7 \\
\hline \multicolumn{3}{|l|}{ ARV regimen during pregnancy } \\
\hline No & 22 & 10.3 \\
\hline Antiretroviral prophylaxis & 95 & 44.4 \\
\hline Antiretroviral tritherapy & 97 & 45.3 \\
\hline
\end{tabular}

Our study also showed that a number of factors were associated with an increased risk of mother-to-child transmission of HIV in exposed children.

Thus, in our work, the risk of being infected with HIV was 8 times higher in 
Table 3. Logistic regression analysis of factors associated with mother to child HIV transmission.

\begin{tabular}{|c|c|c|c|c|c|c|}
\hline & \multicolumn{2}{|c|}{ PCR Result } & \multicolumn{2}{|c|}{ Univariate analysis } & \multicolumn{2}{|c|}{ Multivariate analysis } \\
\hline & Positive & Negative & \multirow{2}{*}{ OR [95\% CI] } & \multirow{2}{*}{$\mathrm{p}$} & \multirow{2}{*}{ aOR $[95 \% \mathrm{CI}]$} & \multirow{2}{*}{$\mathrm{p}$} \\
\hline & $(\mathrm{n}=16)$ & $(\mathrm{n}=198)$ & & & & \\
\hline \multicolumn{7}{|l|}{ Age at PCR } \\
\hline At 6 weeks & 12 & 90 & 1 & & & \\
\hline$>6$ weeks & 4 & 108 & $3.6[1.1-11.5]$ & 0.02 & & \\
\hline \multicolumn{7}{|l|}{ ARV prophylaxis } \\
\hline Yes & 9 & 180 & 1 & & 1 & \\
\hline No & 7 & 18 & $7.8[2.6-23.3]$ & $<0.01$ & $4.3[1.2-15.6]$ & 27 \\
\hline \multicolumn{7}{|l|}{ Cotrimoxazoleto child } \\
\hline Yes & 8 & 156 & 1 & & & \\
\hline No & 8 & 42 & $3.7[1.3-10.5]$ & 9 & & \\
\hline \multicolumn{7}{|l|}{ Mixed feeding } \\
\hline No & 8 & 157 & 1 & & 1 & \\
\hline Yes & 8 & 41 & $3.8[1.3-10.8]$ & 7 & $3.8[1.1-13.2]$ & 31 \\
\hline \multicolumn{7}{|l|}{ Birth weight (g) } \\
\hline$\geq 2500$ & 11 & 161 & 1 & & & \\
\hline$<2500$ & 5 & 37 & $1.9[0.6-6.0]$ & 0.37 & & \\
\hline \multicolumn{7}{|l|}{ Elective caesarean section } \\
\hline Yes & 3 & 80 & 1 & & & \\
\hline No & 13 & 118 & $2.9[0.8-10.6]$ & 0.15 & & \\
\hline \multicolumn{7}{|l|}{ Occupation with income } \\
\hline Yes & 10 & 145 & 1 & & & \\
\hline No & 6 & 53 & $1.6[0.5-4.7]$ & 0.35 & & \\
\hline \multicolumn{7}{|l|}{ Level of education } \\
\hline $\begin{array}{l}\text { Secondary and } \\
\text { higher }\end{array}$ & 11 & 170 & 1 & & & \\
\hline None and primary & 5 & 28 & $2.7[0.9-8.5]$ & 0.14 & & \\
\hline \multicolumn{7}{|l|}{ Marital status } \\
\hline Single & 6 & 57 & 1 & & & \\
\hline In a relationship & 10 & 141 & $1.5[0.5-4.3]$ & 0.46 & & \\
\hline \multicolumn{7}{|l|}{ Number of prenatal consultation } \\
\hline$\geq 4$ & 13 & 191 & 1 & & & \\
\hline$<4$ & 3 & 7 & $6.3[1.4-27.2]$ & 0.03 & & \\
\hline \multicolumn{7}{|l|}{$\begin{array}{l}\text { ARV for the prevention of } \\
\text { mother-to-child HIV transmission }\end{array}$} \\
\hline Yes & 9 & 183 & 1 & & 1 & \\
\hline No & 7 & 15 & $9.5[3.1-29.1]$ & $<0.01$ & $8.0[1.9-32.4]$ & 0.003 \\
\hline \multicolumn{7}{|l|}{ HIV status revealed to the spouse } \\
\hline Yes & 10 & 105 & 1 & & & \\
\hline No & 6 & 93 & $1.5[0.5-4.2]$ & 0.46 & & \\
\hline
\end{tabular}

OR: odds ratio; CI: confidence interval; p: P-value; aOR: adjusted odds ratio. 
children whose mothers had not received any antiretroviral regimen during pregnancy. Our results are consistent with data from the literature. The impact of antiretroviral therapy during pregnancy on the prevention of mother- tochild HIV transmissionis important [14] [15]. In fact, maternal plasma viral load detectable in the vicinity of delivery is by far the most important risk factor of mother to child transmission [8] [16]. Antiretroviral combination therapy by lowering maternal viral load reduces the risk of mother-to-child transmission.

This risk is even almost zero when this antiretroviral tritherapy is initiated from the beginning of pregnancy [3] [8] [17].

Moreover, several observations had shown the need for a minimum of 12 weeks of effective antenatal antiretroviral treatment to control maternal viral load [18] [19].

As in most studies, our series had found a significant association between the lack of antiretroviral prophylaxis in exposed children and mother-to-child transmission. The risk of HIV infection was 4.3 times higher among children who had not received antiretroviral prophylaxis than those who had received antiretroviral prophylaxis. In fact antiretroviral prophylaxis in children exposed minimizes the risk of transmission of HIV during labor and childbirth [12].

Our analysis also showed that the risk of being infected with HIV was significantly higher in the exposed children who had a mixed feeding. Our observation is consistent with those of several previous studies on the role of mixed feeding in increasing the risk of mother to child transmission of HIV infection [20]. The authors converge on the hypothesis that a mixed feeding causes damage to the intestinal wall favoring passage of virus in the blood [21]. Unlike the mixed feed, exclusive breastfeeding and replacement feeding respect the integrity of the intestinal wall of the child [22]. Besidesexclusive breast feeding provides protective immune factors to the child [22].

Unlike other African series, our analysis found no significant association between the mother-child transmission and the age of HIV infection screening by PCR/DBS in exposed children [12] [13].

\section{Study Limitations}

In this study, it is possible that the actual number of infected children is underestimated because PCR/DBS screening of children has still not been done at the end of exposure, ie after weaning for children who were breastfed.

Moreover, the fact that the study is carried out in a CHU, where access to caesarean section, antiretrovirals and PCR is easier (unlike the other healthcare centers in the country), may lead to selection bias, making difficult the extrapolation of our results the general population.

In addition, the retrospective nature of the study may lead to information biases related mainly to missing or incomplete records.

\section{Conclusions}

Despite the remarkable evolution of the recommendations for the prevention of 
mother-to-child transmission of HIV infection, the rate of mother-to-child transmission in our resource-constrained countries remains high. The main factors associated with this mother-to-child transmission of HIV were the absence of antiretroviral therapy during pregnancy, the absence of antiretroviral prophylaxis in the post-natal infant and mixed breastfeeding.

If mother-to-child transmission of HIV is to be eliminated, remedial action should be initiated to address these situations that are not consistent with the recommendations. Thus, it seems important to us to develop strategies to increase the coverage of activities of prevention of mother-to-child HIV transmission.

\section{Financial Support}

None.

\section{Conflict of Interest}

None.

\section{Ethical Considerations}

Due to the retrospective nature of the study, patients' consent was not required. However, the confidentiality of patients' records was respected.

\section{References}

[1] UNAIDS. (2017) Fact Sheet-Latest Statistics on the Status of the AIDS Epidemic. Geneva, Switzerland.

[2] Violari, A., Cotton, M.F., Gibb, D.M., Babiker, A.G., Steyn, J., Mahdi, S.A., et al. (2008) Early Antiretroviral Therapy and Mortality among HIV-Infected Infants. The New England Journal of Medicine, 359, 2233-2244. https://doi.org/10.1056/NEJMoa0800971

[3] European Collaborative Study. (2005) Mother-to-Child Transmission of HIV Infection in the Era of Highly Active Antiretroviral Therapy. Clinical Infectious Diseases, 40, 458-465. https://doi.org/10.1086/427287

[4] Townsend, C.L., Cortina-Borja, M., Peckham, C.S., de Ruiter, A., Lyall, H. and Tookey, P.A. (2008) Low Rates of Mother-to-Child Transmission of HIV Following Effective Pregnancy Interventions in the United Kingdom and Ireland, 2000-2006. Aids, 22, 973-981. https://doi.org/10.1097/QAD.0b013e3282f9b67a

[5] Saizonou, J., Ouedraogo, L., Kpozehouen, A., Bathily, F. and Fayomi, B. (2014) Seroprevalence and Factors Associated with the Serological Status of Children Born to HIV-Positive Mothers in Cotonou Prevention Sites in Benin. Rev. CAMES, 2 , 24-29.

[6] Imade, P.E., Uwakwe, N.O., Omoregie, R. and Eghafona, N.O. (2010) Effect of Prevention of the Mother to Child Transmission Program on the Prevalence of Postnatal HIV Infection in Benin City, Nigeria. Fooyin Journal of Health Sciences, 2, 58-61. https://doi.org/10.1016/S1877-8607(10)60016-1

[7] Côte d'Ivoire Ministry of Public Ministry of Health and Public Hygiene (2015) Guidelines 2015 for Life-Long Antiretroviral Treatment of Pregnant Women 
Infected with HIV/AIDS in the Prevention of Mother-to-Child Transmission of HIV (PMTCT) in Côte d'Ivoire. Abidjan.

[8] Warszawski, J., Tubiana, R., Le Chenadec, J., Blanche, S., Teglas, J.-P., Dolfus, C., et al. (2008)Mother-to-Child HIV Transmission despite Antiretroviral Therapy in the ANRS French Perinatal Cohort. AIDS, 22, 289-299. https://doi.org/10.1097/QAD.0b013e3282f3d63c

[9] Newell, M.L., Huang, S., Fiore, S., Thorne, C., Mandelbrot, L., Sullivan, J.L., et al. (2007) Characteristics and Management of HIV-1-Infected Pregnant Women Enrolled in a Randomised Trial: Differences between Europe and the USA. BMC Infectious Diseases, 7, 60. https://doi.org/10.1186/1471-2334-7-60

[10] Martin, F., Palladino, C., Mateus, R., Bolzan, A., Gomes, P., Brito, J., et al. (2017) Early Infant Diagnosis of HIV-1 Infection in Luanda, Angola, Using a New DNA PCR Assay and Dried Blood Spots. PLoS ONE, 12, e0181352. https://doi.org/10.1371/journal.pone.0181352

[11] Technau, K.G., Mazanderani, A.H., Kuhn, L., Hans, L., Strehlau, R., Abrams, E.J., et al. (2017) Prevalence and Outcomes of HIV-1 Diagnostic Challenges during Universal Birth Testing-An Urban South African Observational Cohort. Journal of the International AIDS Society, 20, 48-56. https://doi.org/10.7448/IAS.20.7.21761

[12] Berhan, Z., Abebe, F., Gedefaw, M., Tesfa, M., Assefa, M. and Tafere, Y. (2014) Risk of HIV and Associated Factors among Infants Born to HIV Positive Women in Amhara Region, Ethiopia: A Facility Based Retrospective Study. BMC, 7, 876. https://doi.org/10.1186/1756-0500-7-876

[13] Noubiap, J.J., Bongoe, A. and Demanou, S.A. (2013) Mother-to-Child Transmission of HIV: Findings from an Early Infant Diagnosis Program in Bertoua, Eastern Cameroon. Pan African Medical Journal, 15, 65.

[14] Ngwej, D.T., Mukuku, O., Mudekereza, R., Karaj, E., Odimba, E.B., Luboya, O.N., et al. (2015) Study of Risk Factors for HIV Transmission from Mother to Child in the Strategy "option A" in Lubumbashi, Democratic Republic of Congo. Pan African Medical Journal, 22,18.

[15] Cooper, E.R., Charurat, M., Mofenson, L., Hanson, I.C., Pitt, J., Diaz, C., et al. (2002) Combination Antiretroviral Strategies for the Treatment of Pregnant HIV-1-Infected Women and Prevention of Perinatal HIV-1 Transmission. Journal of Acquired Immune Deficiency Syndromes, 29, 484-494.

https://doi.org/10.1097/00042560-200204150-00009

[16] O’Donovan, D., Ariyoshi, K., Milligan, P., Ota, M., Yamuah, L., Sarge-Njie, R., et al. (2000)Maternal Plasma Viral RNA Levels Determine Marked Differences in Mother-to-Child Transmission Rates of HIV-1 and HIV-2 in the Gambia. MRC/Gambia Government/University College London Medical School Working Group on Mother-Child Transmission of HIV. AIDS, 14, 441-448.

https://doi.org/10.1097/00002030-200003100-00019

[17] Tubiana, R., Le Chenadec, J., Rouzioux, C., Mandelbrot, L., Hamrene, K., Dollfus, C., et al. (2010) Factors Associated with Mother-to-Child Transmission of HIV-1 Despite a Maternal Viral Load < 500 Copies/ml at Delivery: A Case-Control Study Nested in the French Perinatal Cohort (EPFANRS CO1). Clinical Infectious Diseases, 50, 585-596. https://doi.org/10.1086/650005

[18] Chibwesha, C.J., Giganti, M.J., Putta, N., Chintu, N., Mulindwa, J., Dorton, B.J., et al. (2011) Optimal Time on HAART for Prevention of Mother-to-Child Transmission of HIV. Journal of Acquired Immune Deficiency Syndromes, 58, 224-228. https://doi.org/10.1097/QAI.0b013e318229147e 
[19] Patel, D., Cortina-Borja, M., Thorne, C. and Newell, M.L. (2007) Time to Undetectable Viral Load after Highly Active Antiretroviral Therapy Initiation among HIV-Infected Pregnant Women. Clinical Infectious Diseases, 44, 1647-1656. https://doi.org/10.1086/518284

[20] Becquet, R., Ekouevi, D.K., Menan, H., Amani-Bosse, C., Bequet, L., Viho, I., et al. (2008) Early Mixed Feeding and Breastfeeding beyond 6 Months Increase the Risk of Postnatal HIV Transmission: ANRS 1201/1202 Ditrame Plus, Abidjan, Côte d'Ivoire. Preventive Medicine, 47, 27-33.

https://doi.org/10.1016/j.ypmed.2007.11.014

[21] Coovadia, H.M., Rollins, N.C., Bland, R.M., Little, K., Coutsoudis, A., Bennish, M.L., et al. (2007) Mother-to-Child Transmission of HIV-1 Infection during Exclusive Breastfeeding in the First 6 Months of Life: An Intervention Cohort Study. The Lancet, 369, 1107-1116. https://doi.org/10.1016/S0140-6736(07)60283-9

[22] Fouda, G.G., Jaeger, F.H., Amos, J.D., Ho, C., Kunz, E.L., Anasti, K., et al. (2013) Tenascin-C Is an Innate Broad-Spectrum, HIV-1-Neutralizing Protein in Breast Milk. Proceedings of the National Academy of Sciences of the United States of America, 110, 18220-18225. https://doi.org/10.1073/pnas.1307336110 